\title{
Reimplante mediato de dentes tratados ou não com solução de hipoclorito de sódio a $1 \%$ - estudo histomorfométrico em ratos
}

\section{Effects of sodium hypochlorite on periodontal healing after tooth replantation - histomorphometric study in rats}

\author{
Cláudia Misue KANNO* \\ Michel SAAD NETO** \\ Maria Lúcia Marçal Mazza SUNDFELD*** \\ Marina del Pilar VELASCO-BOHÓRQUES ${ }^{* * * *}$
}

\begin{abstract}
KANNO, C. M.; SAAD NETO, M.; SUNDFELD, M. L. M. M., VELASCO-BOHÓRQUES, M. P. Reimplante mediato de dentes tratados ou não com solução de hipoclorito de sódio a $1 \%$ - estudo histomorfométrico em ratos. Pesq Odont Bras, v. 14, n. 2, p. 151-157, abr./jun. 2000.
\end{abstract}

\begin{abstract}
Foi avaliada a influência do hipoclorito de sódio a $1 \%$ no reparo do periodonto de incisivos reimplantados tardiamente em ratos. Os dentes foram mantidos em meio ambiente durante 30 minutos e a seguir imersos em hipoclorito de sódio a 1\%, por 25 minutos. Os animais foram sacrificados aos 10, 30 ou 60 dias. Os cortes histológicos foram obtidos no sentido transversal dos terços cervical, médio e apical e delineados com um aumento de 52 vezes. Os eventos observados sobre a superficie radicular foram medidos quanto a sua extensão através de um sistema analisador de imagens (Mini-Mop, Carl Zeiss). Aos 10 dias, observou-se a predominância de tecido conjuntivo fibroso no grupo tratado. Aos 30 e 60 dias observou-se o aumento da anquilose e reabsorção por substituição, assim como neoformação limitada de ligamento periodontal. No grupo controle, aos 30 e 60 dias, foram observadas áreas de reabsorções mais extensas e profundas, quando comparadas ao grupo tratado. Os resultados possibilitaram as seguintes conclusões quando comparado o grupo tratado com o controle: a) leva à formação de tecido conjuntivo semelhante a uma cápsula fibrosa no período inicial do reparo; b) possibilita uma limitada neoformação de ligamento periodontal; c) ocasiona uma superfície de anquilose mais extensa; d) não impede a reabsorção por substituição.
\end{abstract}

UNITERMOS: Reimplante dental; Hipoclorito de sódio; Reabsorção da raiz.

\section{INTRODUÇÃO}

A principal causa de perda de dentes reimplantados é a reabsorção radicular decorrente da necrose do ligamento periodontal ${ }^{2,11}$, da contaminação do elemento dental ${ }^{2}$ e do trauma sobre a superficie radicular. Desta forma, pesquisas têm sido realizadas com o intuito de estabelecer tratamentos que controlem a reabsorção e a subseqüente perda de um dente reimplantado.

O cemento é considerado como a última barreira biológica protetora da dentina, além de possuir substâncias com atividade mitogênica ${ }^{17,22}$. Pesquisas sobre reimplante dental indicam que a remoção química do ligamento periodontal permite manter o cemento intacto ${ }^{11,19}$.

A solução de hipoclorito de sódio é conhecida pela sua capacidade germicida e de dissolução de matéria orgânica. Tais características são diretamente proporcionais à concentração da solução ${ }^{9}$, assim como a sua toxicidade ${ }^{10}$. A dissolução de tecidos orgânicos é maior nos tempos iniciais de exposição à solução ${ }^{5,15}$, que é consideravelmente aumentada com trocas contínuas ${ }^{7}$.

Tendo em vista estas considerações, o propósito do presente trabalho é analisar, em ratos, o reparo do periodonto de incisivos tratados com hipoclorito de sódio a $1 \%$ e reimplantados tardiamente.

\section{MATERIAL E MÉTODO}

Para a realização do presente trabalho, foram utilizados 24 ratos (Rattus norvegicus, Wistar) machos. O incisivo superior direito de cada animal foi

* Professora do Curso de Odontologia de Umuarama da UNIPAR.

** Professor Titular de Cirurgia e Traumatologia Buco-Maxilo-Facial; *** Professora Assistente da Disciplina de Bioestatística;

**** Doutora em Odontologia - Faculdade de Odontologia de Araçatuba da UNESP. 
KANNO, C. M.; SAAD NETO, M.; SUNDFELD, M. L. M. M., VELASCO-BOHÓRQUES, M. P. Reimplante mediato de dentes tratados ou não com solução de hipoclorito de sódio a $1 \%$ - estudo histomorfométrico em ratos. Pesq Odont Bras, v. 14, n. 2, p. 151-157, abr./jun. 2000.

luxado e extraído, mantido em meio ambiente com a face mesial sobre um campo esterilizado, à temperatura aproximada de $22^{\circ} \mathrm{C}$, por um período de 30 minutos.

A polpa foi extirpada por via retrógrada, com lima endodôntica $n^{\circ} 15$, enquanto o dente era envolto em gaze umedecida com soro fisiológico. Cada dente foi colocado em frasco individual de vidro âmbar, contendo $4 \mathrm{ml}$ de solução de hipoclorito de sódio a 1\% (solução de Milton, Merrel Lepetit Farmacêutica Ltda.), pH 12, com trocas a cada cinco minutos. Os dentes dos animais do grupo controle foram imersos em água bidestilada, que também foi trocada a cada cinco minutos. Após 25 minutos, os dentes dos dois grupos foram imersos em água bidestilada, por cinco minutos. Todos os dentes foram irrigados com água bidestilada e seu canais preenchidos com rifamicina (Rifocina M $75 \mathrm{mg}$, Merrel Lepetit). Em seguida, os dentes foram reimplantados. Em cada animal foi aplicado $1 \mathrm{ml}$ de rifamicina, por via intraperitoneal.

Quatro animais de cada grupo foram sacrificados por inalação excessiva de éter sulfúrico, aos 10,30 ou 60 dias após o reimplante. As hemimaxilas direitas foram fixadas em formol tamponado a
$10 \%$ por 24 horas, lavadas e descalcificadas em solução de citrato de sódio a $20 \%$ e ácido fórmico a $50 \%$, em partes iguais. Os cortes histológicos das peças incluídas em parafina foram obtidos no sentido transversal, dos terços cervical, médio e apical e corados com hematoxilina e eosina.

Para a análise histomorfométrica, um corte histológico representativo de cada terço, de cada dente, foi delineado com um aumento de 52 vezes, com o auxílio de um aparelho projetor de lâminas ao qual foi acoplada uma câmara clara. Em cada desenho foi marcado o limite de cada evento observado sobre a superficie radicular, através da análise do respectivo corte no microscópio de luz. A face do dente que era recoberta por esmalte não foi considerada.

As extensões de cada evento observado sobre as superficies radiculares foram mensuradas através de um sistema analisador de imagens (Mini-Mop, Carl Zeiss / Fapesp - Processo no 88/1208-0), programado para medir comprimento e calibrado para fornecer os dados em milimetros, com uma diminuição compensatória de 52 vezes. As partes das superficies radiculares que sofreram reabsorções

TABELA 1 - Médias dos eventos observados sobre a superficie radicular. Dados em proporção.

\begin{tabular}{|c|c|c|c|c|c|c|}
\hline \multirow{2}{*}{ Eventos } & \multicolumn{3}{|c|}{ Grupo controle } & \multicolumn{3}{|c|}{ Grupo tratado } \\
\hline & 10 dias & 30 dias & 60 dias & 10 dias & 30 dias & 60 dias \\
\hline Ligamento periodontal* & 0,6537 & 0,1736 & 0,1517 & 0 & 0,0201 & 0,0307 \\
\hline Ligamento periodontal ossificado & 0,0652 & 0 & 0 & 0,0045 & 0,0399 & 0 \\
\hline Lig. period. junto a tecido conjuntivo & 0,0158 & 0 & 0 & 0,2068 & 0,0081 & 0 \\
\hline Lig. period. junto a tecido ósseo & 0 & 0,0111 & 0 & 0,0070 & 0,0756 & 0,0187 \\
\hline Anquilose** & 0,0503 & 0,2286 & 0,1304 & 0,0846 & 0,3001 & 0,3828 \\
\hline Anquilose com interposição de células & 0 & 0 & 0 & 0,0805 & 0,0829 & 0 \\
\hline Reabsorção de superfície & 0,1001 & 0,0257 & 0 & 0 & 0,0163 & 0,0061 \\
\hline Reabsorção de substituição ativa & 0,0183 & 0,0091 & 0 & 0 & 0,035 & 0,0098 \\
\hline Reabsorção de substituição cessada & 0,0655 & 0,0828 & 0,0960 & 0 & 0,0402 & 0,0816 \\
\hline Reabsorção de substituição reparada*** & 0,0060 & 0,4167 & 0,5487 & 0 & 0,2652 & 0,4019 \\
\hline Tecido conjuntivo denso & 0,0251 & 0,0038 & 0,0132 & 0,0842 & 0,0340 & 0,0165 \\
\hline Tecido conjuntivo fibroso & 0 & 0,0036 & 0,0418 & 0,4801 & 0,0879 & 0,0397 \\
\hline Tecido conjuntivo frouxo & 0 & 0,0113 & 0,0019 & 0,0523 & 0,0262 & 0,0122 \\
\hline Comunicação entre polpa e periodonto & 0 & 0,0337 & 0,0163 & 0 & 0 & 0 \\
\hline
\end{tabular}

*Diferença estatisticamente significativa entre os grupos controle e tratado, quando comparados no mesmo tempo experimental. ${ }^{* *}$ Diferença estatisticamente significativa entre os grupos controle e tratado, aos 60 dias. ${ }^{* * *}$ Diferença estatisticamente significativa entre os grupos controle e tratado, aos 30 dias. 
KANNO, C. M.; SAAD NETO, M.; SUNDFELD, M. L. M. M., VELASCO-BOHÓRQUES, M. P. Reimplante mediato de dentes tratados ou não com solução de hipoclorito de sódio a $1 \%$ - estudo histomorfométrico em ratos. Pesq Odont Bras, v. 14, n. 2, p. 151-157, abr./jun. 2000.

foram reconstruídas em seu contorno inicial, antes de serem mensuradas.

Os valores obtidos, em milímetros, foram calculados em proporção, considerando-se como superficie total aquela compreendida entre os dois extremos da face recoberta por esmalte. Os dados em proporção referentes ao ligamento periodontal, reabsorção por substituição e anquilose foram transformados em arco seno e analisados estatisticamente, através de análise de variância, ao nivel de significância de 5\%.

\section{RESULTADOS}

Os valores das médias dos eventos observados sobre a superficie radicular, assim como o resultado da análise estatística, podem ser vistos na Tabela 1.

Pode-se observar o predomínio de tecido conjuntivo fibroso no grupo tratado, aos 10 dias. Este tecido apresentava fibras colágenas paralelas à superficie radicular, de forma semelhante a uma cápsula fibrosa. Em algumas áreas, notadamente proximais, foram observados remanescentes acelulares de fibras periodontais e ausência de reação inflamatória ou de corpo estranho. No grupo controle, no mesmo período, o ligamento periodontal foi o tipo de tecido mais observado.

Aos 30 dias, no grupo tratado, observa-se acentuada diminuição de tecido conjuntivo denso, fibroso e frouxo e um aumento da anquilose alvéolo-dental. O tecido conjuntivo fibroso apresen-

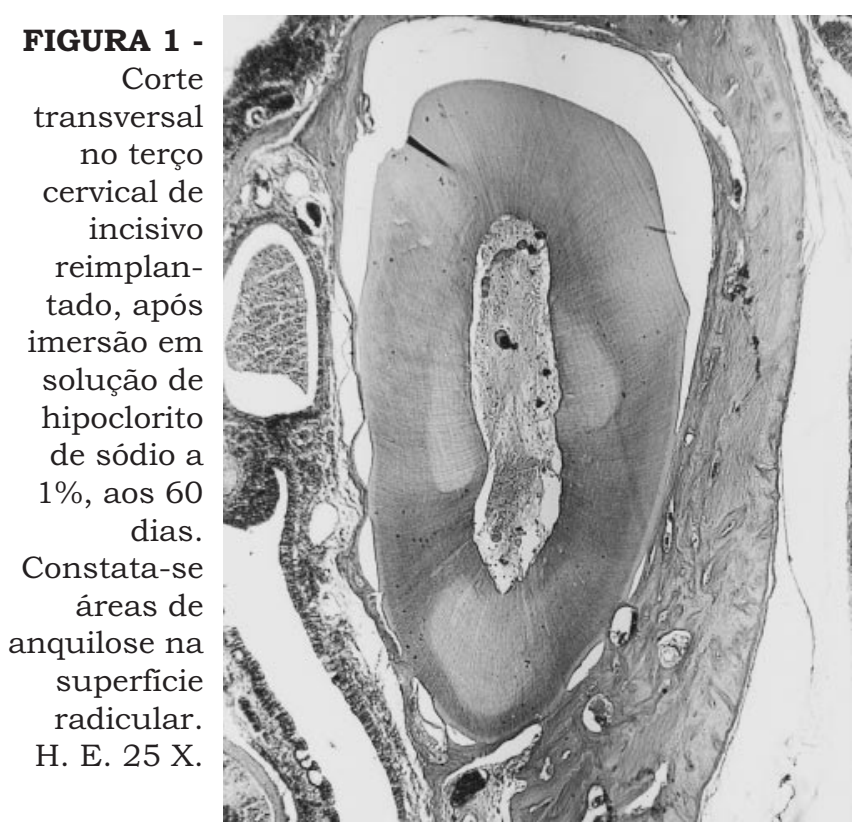

tou-se mais delgado, muitas vezes interposto entre tecido ósseo e dente (anquilose com interposição de células). Algumas áreas limitadas apresentaram tecido conjuntivo com fibras colágenas inseridas perpendicularmente à superficie radicular, com uma camada de células semelhantes a cementoblastos (ligamento periodontal). No grupo controle, comparando-se ao periodo anterior, observa-se um aumento da ocorrência de reabsorção por substituição, principalmente a reparada. O ligamento periodontal foi observado muitas vezes sobre superficie radicular previamente reabsorvida.

No grupo tratado, aos 60 dias, observa-se predominância de anquilose e reabsorção por substituição reparada (Figura 1). Constatou-se a incorporação de fibras remanescentes de ligamento periodontal ao tecido ósseo em algumas áreas. $\mathrm{O}$ ligamento periodontal (Figura 2) pôde ser observado em $3,07 \%$ da superficie. No mesmo período, observa-se a manutenção da média do ligamento periodontal (Figura 3) no grupo controle. Comparando-se com o grupo tratado, as reabsorções radiculares foram mais extensas e profundas (Figura 4).

\section{DISCUSSÃO}

No grupo tratado, procurou-se compensar a baixa capacidade de dissolução da solução de hipoclorito de sódio na concentração de $1 \%$ com trocas a cada cinco minutos ${ }^{7}$. No entanto, obser-

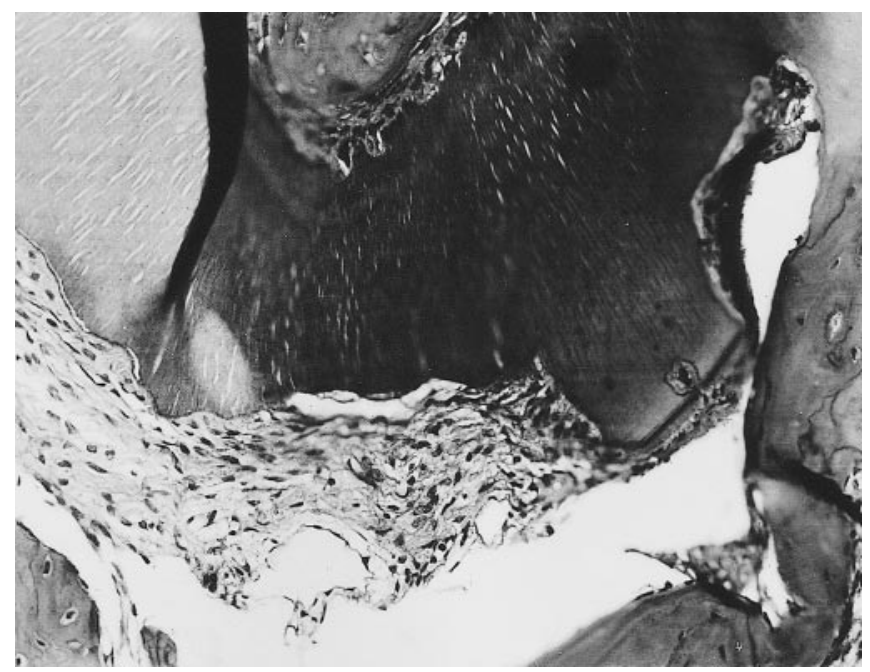

FIGURA 2 - Superfície radicular palatina de incisivo reimplantado, após imersão em solução de hipoclorito de sódio a $1 \%$. Reinserção de ligamento periodontal na superficie reabsorvida, aos 60 dias. H. E. 160 X. 
KANNO, C. M.; SAAD NETO, M.; SUNDFELD, M. L. M. M., VELASCO-BOHÓRQUES, M. P. Reimplante mediato de dentes tratados ou não com solução de hipoclorito de sódio a $1 \%$ - estudo histomorfométrico em ratos. Pesq Odont Bras, v. 14, n. 2, p. 151-157, abr./jun. 2000.

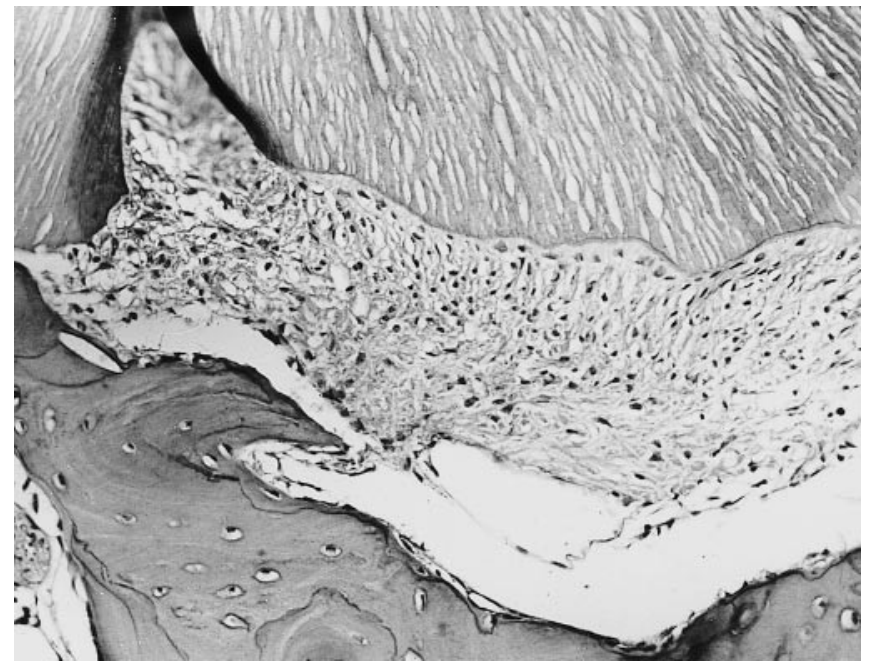

FIGURA 3 - Ligamento periodontal presente na superficie radicular reabsorvida de incisivo reimplantado, após imersão em água bidestilada. 60 dias. H. E. 160 X.

vou-se remanescentes acelulares de ligamento periodontal aos dez dias, que foram calcificados e envolvidos por tecido ósseo nos períodos subseqüentes. Tem sido observado que tecidos necrosados e não contaminados causam pequena ou nenhuma reação inflamatória ${ }^{12}$, o que parece justificar a não interferência de tais remanescentes no processo de reparo.

Nas áreas em que o ligamento periodontal foi totalmente removido pelo tratamento, foi observada predominância de tecido conjuntivo fibroso, semelhante a uma cápsula fibrosa, que não foi observada em nenhum espécime do grupo controle. Nos períodos mais longos, verificou-se a diminuição progressiva deste tecido, em alguns casos, dando lugar a uma anquilose com interposição de células. Essa disposição de tecido conjuntivo paralela à superficie radicular também foi descrita em trabalhos realizados in vitro ${ }^{23}$ e in vivo ${ }^{4,18}$, nos quais não foi realizada desmineralização artificial da superficie radicular. PITARU; MELCHER $(1987)^{20}$ acreditam que a formação deste tipo de tecido seja um reflexo fenotípico de uma subpopulação específica de fibroblastos.

Em um estudo, dentes de macacos foram mantidos em solução de hipoclorito de sódio a $10 \%$, durante uma hora, previamente ao reimplante ${ }^{11}$. Os autores verificaram que este tratamento ocasionou áreas de anquilose, sem reabsorções da superfície radicular. Na maioria dos pontos analisados, uma camada amorfa basofilica foi observada de forma intermintente, interposta entre o tecido ósseo e o

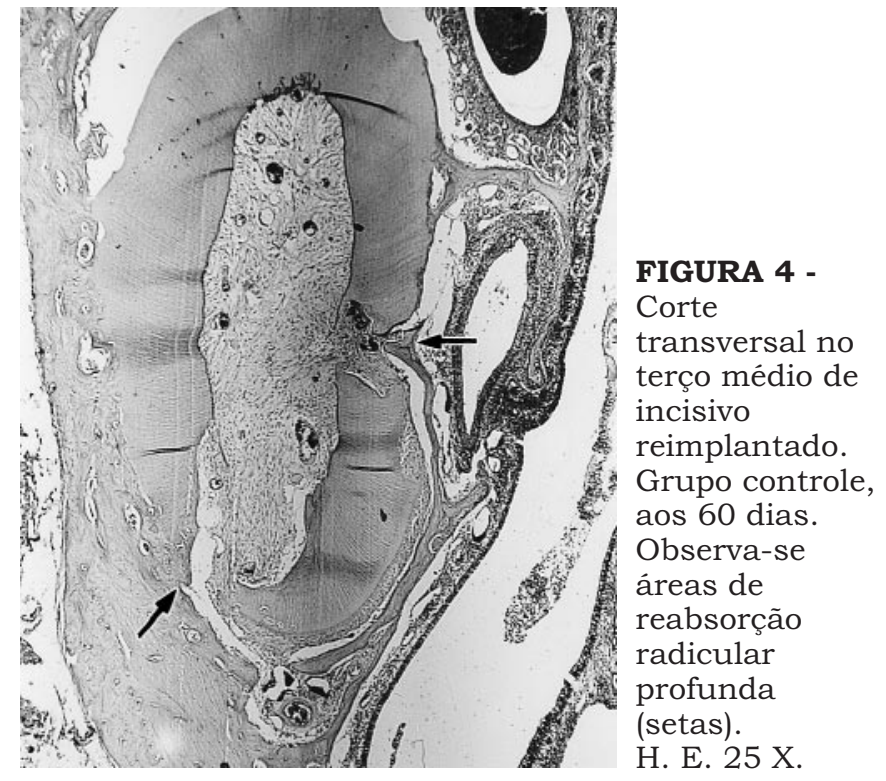

cemento, que foi atribuída a remanescentes necróticos de osteoblastos e de células circunjacentes ao osso. Os autores observaram ligamento periodontal em $1 \%$ do total da superficie radicular. A ausência de reabsorções radiculares descrita por estes autores, ao contrário dos resultados obtidos no presente trabalho, pode ser atribuída às diferenças de metodologia. É possível, porém, que seja uma etapa anterior do reparo após o reimplante dental, tendo em vista que cada animal apresenta tempos diferentes deste processo. A camada amorfa basofilica pode representar um estágio mais tardio do que foi descrito no presente trabalho como anquilose com interposição de células.

A presença de ligamento periodontal, no grupo tratado, aos trinta e sessenta dias, em quantidade estatisticamente maior em relação ao grupo de dez dias, poderia ser justificada pela migração e diferenciação das células progenitoras paravasculares ${ }^{13,14,21}$. Acreditamos nesta possibilidade, pois o hipoclorito de sódio torna inviáveis para cultivo in vitro, células do ligamento periodontal, após a imersão de raízes na solução a $5 \%$, durante dois minutos $^{24}$. Desta forma, no processo de reparo no presente trabalho, é improvável a participação das células progenitoras do ligamento periodontal localizado próximo ao cemento.

A maioria dos fatores de crescimento que participam do processo de diferenciação de células progenitoras origina-se de células circunjacentes ${ }^{1,28}$. Estes dados indicam que, durante o processo de regeneração de um tecido, são importantes todos 
KANNO, C. M.; SAAD NETO, M.; SUNDFELD, M. L. M. M., VELASCO-BOHÓRQUES, M. P. Reimplante mediato de dentes tratados ou não com solução de hipoclorito de sódio a $1 \%$ - estudo histomorfométrico em ratos. Pesq Odont Bras, v. 14, n. 2, p. 151-157, abr./jun. 2000.

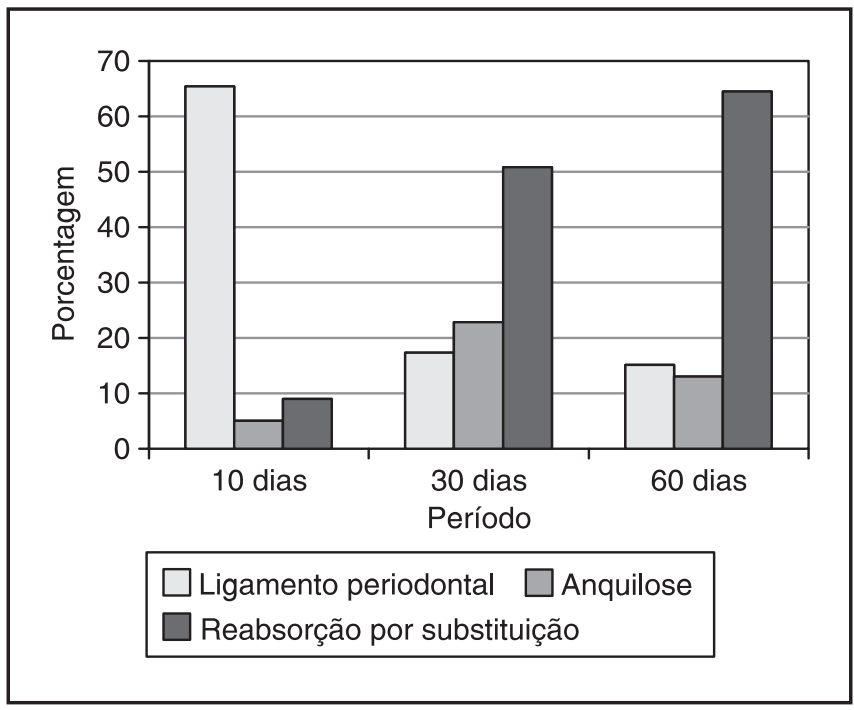

GRÁFICO 1 - Média dos eventos em percentagem - grupo controle.

os seus elementos celulares. A provável ausência da população celular do ligamento periodontal aderido à superficie radicular, assim como os fatores que mantêm a sua diferenciação, podem justificar o fato de que o ligamento periodontal observado no grupo tratado aos trinta e sessenta dias, não tenha apresentado características normais.

Apesar da possibilidade de neoformação de ligamento periodontal, observou-se a predominância de um reparo caracterizado pela formação de tecido ósseo (Gráficos 1 e 2 - anquilose e reabsorção por substituição). Em um estudo foi observada a manifestação fenotípica cementoblástica de células colhidas de tecido ósseo periodontal e cultivadas in vitro ${ }^{14}$, o que indica o potencial de diferenciação em cementoblastos. No entanto, é possivel que a interação de fatores, durante o processo de reparo após o reimplante dental tardio, favoreça a diferenciação das células progenitoras do tecido ósseo em osteoblastos, além do fato de cementoblastos e osteoblastos apresentarem características fenotípicas em comum ${ }^{26,27}$.

No presente trabalho, foi observado que a reinserção periodontal aos trinta e sessenta dias, geralmente, era precedida por reabsorção da superficie radicular, tanto no grupo controle como no tratado. Essa constatação nos leva a acreditar que proteínas do cemento e dentina ${ }^{16,17,22}$ podem participar do desenvolvimento do fenótipo cementoblástico em células progenitoras ${ }^{22}$. Outra possibilidade de liberação dos fatores de crescimento do

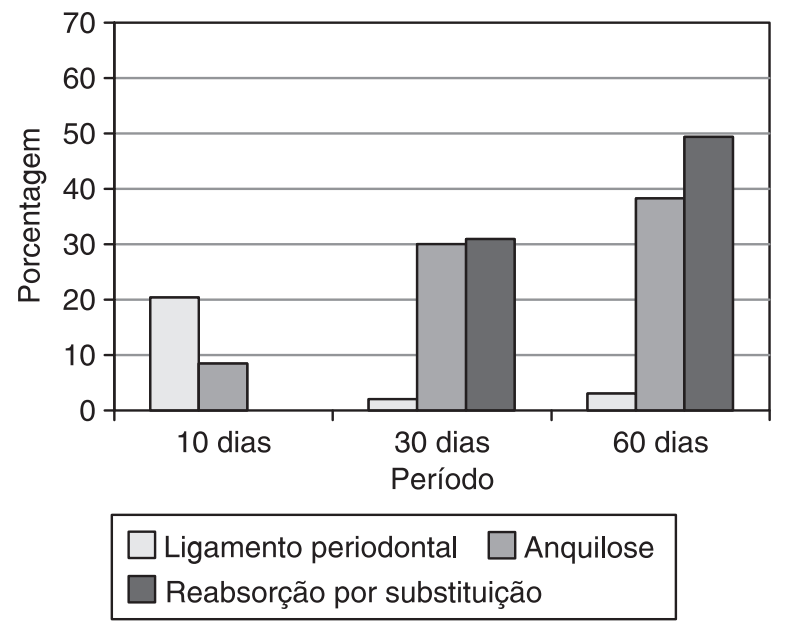

GRÁFICO 2 - Média dos eventos em percentagem - grupo tratado.

cemento é a causada pela desmineralização artificial da superficie radicular. Este procedimento confere uma superfície mais favorável à adesão de células in vitro, quando comparada à superficie não desmineralizada ${ }^{3}$. Sabe-se que o Fator de Crescimento derivado do Cemento (CGF) liga-se aos componentes minerais da raiz ${ }^{22}$, que parecem "esconder" os fatores quimiotáticos ${ }^{17}$.

Reimplantes foram realizados em cães, após a manutenção dos dentes com ligamento periodontal com vitalidade em solução de hipoclorito de sódio a $5 \%$, durante uma hora ${ }^{19}$. Antes do reimplante, os dentes foram imersos em ácido cítrico a $10 \%$, durante um minuto. Este tratamento possibilitou a reinserção de fibras colágenas sobre cemento neoformado. $\mathrm{Na}$ análise dos dados deste trabalho, deve-se considerar que a regeneração do periodonto de cães parece ocorrer mesmo em condições adversas $^{6,8}$. No presente trabalho não se efetuou a imersão do dente em solução ácida, baseados em trabalhos descritos na literatura, que contra-indicam este procedimento em dentes a serem reimplantados com seu ligamento periodontal necrosado ${ }^{25}$. No entanto, a possibilidade da desmineralização da superficie radicular expor fatores de crescimento presentes no cemento e resultados altamente favoráveis obtidos em estudos prévios ${ }^{19}$, apesar das diferenças metodológicas, sugerem que o tratamento com ácido em reimplantes de dentes tratados com hipoclorito de sódio deva ser reconsiderado. 
KANNO, C. M.; SAAD NETO, M.; SUNDFELD, M. L. M. M., VELASCO-BOHÓRQUES, M. P. Reimplante mediato de dentes tratados ou não com solução de hipoclorito de sódio a $1 \%$ - estudo histomorfométrico em ratos. Pesq Odont Bras, v. 14, n. 2, p. 151-157, abr./jun. 2000.

A tentativa de um reimplante dental tardio sempre é válida. Embora a anquilose seja um resultado longe do ideal, possibilita a permanência do elemento dental por muitos anos. Contudo, a vitalidade do ligamento periodontal é essencial para a permanência longa do dente reimplantado.

\section{CONCLUSÕES}

Os resultados obtidos no presente trabalho permitem concluir que o tratamento com hipoclorito de sódio a $1 \%$, previamente ao reimplante dental tardio, em ratos, quando comparado à imersão em água bidestilada:

- leva à formação de um tecido conjuntivo semelhante a uma cápsula fibrosa no período inicial de reparo;

- possibilita uma limitada neoformação de ligamento periodontal;

- ocasiona uma superficie de anquilose mais extensa;

- não impede a reabsorção por substituição.

KANNO, C. M.; SAAD NETO, M.; SUNDFELD, M. L. M. M.; VELASCO-BOHÓRQUES, M. P. Effects of sodium hypochlorite on periodontal healing after tooth replantation - histomorphometric study in rats. Pesq Odont Bras, v. 14, n. 2, p. 151-157, abr./jun. 2000.

The aim of the present study was to examine the influence of $1 \%$ sodium hypochlorite on periodontal healing after tooth replantation. Rats incisors were extracted, maintained in the environment during 30 minutes, then immersed in $1 \%$ sodium hypochlorite for 30 minutes. In the control group, the teeth were maintained in distilled water. The animals were sacrificed after 10, 30 and 60 days. Transversal slices of the teeth were obtained and histologically processed through the hematoxylin and eosin technique. Slices from the cervical, middle and apical thirds of each tooth were selected for the analysis. The slices were projected and outlined. The tissues observed on the dental surfaces were measured with an image analysing system (Mini-Mop, Carl Zeiss). In the 10-day treated group, the main characteristic observed was a connective tissue arranged parallelly to the root surface, although not attached to it. After 30 and 60 days, the connective tissue was reduced and an increase of ankylosis was observed, as well as replacement resorption. A limited periodontal ligament reattachment was also observed. In the control group, the periodontal ligament was preserved in about $15 \%$ to $17 \%$ of the root surface after 30 and 60 days, and the resorption areas were deeper than in the treated group. It was concluded that $1 \%$ sodium hypochlorite allowed an increase of the ankylosed root surface and a limited periodontal ligament reattachment, but did not avoid replacement resorption.

UNITERMS: Tooth replantation; Sodium hypochlorite; Root resorption.

\section{REFERÊNCIAS BIBLIOGRÁFICAS}

1. ALBERTS, B.; BRAY, D.; LEWIS, J. et al. Molecular biology of the cell. 3. ed. New York : Garland Publishing Inc., 1994. 1294 p.

2. ANDREASEN, J. O. Relationship between cell damage in the periodontal ligament after replantation and subsequent development of root resorption. A time-related study in monkeys. Acta Odont Scand, v. 39, n. 1, p. 15-25, 1981.

3. BOYKO, G. A.; BRUnetTe, D. M.; MElChER, A. H. Cell attachment to demineralized root surfaces in vitro. $\mathbf{J} \mathbf{P e}-$ riodontal Res, v. 15, n. 3, p. 297-303, May 1980.

4. BOYKO, G. A.; MELChER, A. H.; BRUNETTE, D. M. Formation of new periodontal ligament by periodontal ligament cells implanted in vivo after culture in vitro. A preliminary study of transplanted roots in the dog. $\mathbf{J}$ Periodontal Res, v. 16, n. 1, p. 73-88, Jan. 1981.

5. GORDON, T. M.; DAMATO, D.; CHRISTNER, P. Solvent effect of various dilutions of sodium hypochlorite on vital and necrotic tissue. J Endod, v. 7, n. 10, p. 466-469, Oct. 1981

6. GROPER, J. N.; BERNICK, S. Histological study of the periodontium following replantation of teeth in the dog. $\mathbf{J}$ Dent Child, v. 37, p. 25-35, Jan./Feb. 1970.
7. HASSELGREN, G.; OLSON, B.; CVEK, M. Effects of calcium hydroxide and sodium hypochlorite on the dissolution of necrotic porcine muscle tissue. J Endod, v. 14, n. 3, p. 125-127, Mar. 1988.

8. JANSEN, J.; CORBA, N. H. C.; PILOT, T. et al. Spontaneous regeneration of artificially created periodontal defects in Beagle dogs. J Dent Res, v. 58, Sp. Iss. A, p. 240, 1979.

9. KOSKINEN, K. P.; STENVALL, H.; UITTO, V. J. Dissolution of bovine pulp tissue by endodontic solutions. Scand $\mathbf{J}$ Dent Res, v. 88, n. 5, p. 406-411, Oct. 1980.

10. KOSKINEN, K. P.; RAHKAMO, A.; TUOMPO, H. Cytotoxicity of some solutions used for root canal treatment assessed with human fibroblasts and lymphoblasts. Scand $\mathbf{J}$ Dent Res, v. 89, n. 1, p. 71-78, Oct. 1981.

11. LINDSKOG, S.; PIERCE, A. M..; BLOMLÖF, L. et al. The role of the necrotic periodontal membrane in cementum resorption and ankylosis. Endod Dent Traumatol, v. 1, n. 3, p. 96-101, Jun. 1985.

12. MAKKES, P. C.; VAN VELZEN, S. K. T.; VAN DEN HOOFF, A. The response of the living organism to dead and fixed dead enclosed homologous tissue. Oral Surg Oral Med Oral Pathol, v. 46, n. 2, p. 296-306, Aug. 1978.

13. McCULLOCH, C. A. G. Progenitor cell populations in the periodontal ligament of mice. Anat Rec, v. 211, n.3, p. 258-262, Mar. 1985. 
KANNO, C. M.; SAAD NETO, M.; SUNDFELD, M. L. M. M., VELASCO-BOHÓRQUES, M. P. Reimplante mediato de dentes tratados ou não com solução de hipoclorito de sódio a 1\% - estudo histomorfométrico em ratos. Pesq Odont Bras, v. 14, n. 2, p. 151-157, abr./jun. 2000.

14. MELCHER, A. H.; CHEONG, T.; COX, J. et al. Synthesis of cementum-like tissue in vitro by cells cultured from bone: a light and electron microscope study. J Periodontal Res, v. 21, n. 6, p. 592-612, Nov. 1986.

15. MOORER, W. R.; WESSELINK, P. R. Factors promoting the tissue dissolving capability of sodium hypochlorite. Int Endod J, v. 15, n. 4, p. 187-196, Oct. 1982.

16. NARAYANAN, S. A.; YONEMURA, K. Purification and characterization of a novel growth factor from cementum. $\mathbf{J}$ Periodontal Res, v. 28, n. 6Pt2, p. 563-565, Nov. 1993.

17. NISHIMURA, K.; HAYASHI, M.; MATSUDA, K. et al. The chemoattractive potency of periodontal ligament, cementum and dentin for human gingival fibroblasts. $\mathbf{J}$ Periodontal Res, v. 24, n. 2, p.146-148, Mar. 1989.

18. NYMAN, S.; KARRING, T.; LINDHE, J. et al. Healing following implantation of periodontitis-affected roots into gingival connective tissue. J Clin Periodontol, v. 7, n. 5, p. 394-401, Oct. 1980.

19. PERCINOTO, C.; RUSSO, M. C.; LIMA, J. E. O. et al. Processo de reparo em dentes reimplantados após a remoção química das fibras periodontais radiculares. Rev Odontol UNESP, v. 17, n. 1/2, p. 73-81, 1988.

20. PITARU, S.; MELCHER, A. H. Organization of an oriented fiber system in vitro by human gingival fibroblasts attached to dental tissue: relationship between cells and mineralized and demineralized tissue. J Periodontal Res, v. 22, n. 1, p.6-13, Jan. 1987.

21. PITARU, S.; McCULLOCH, C. A. G.; NARAYANAN, S. A. Cellular origins and differentiation control mechanisms during periodontal development and wound healing. $\mathbf{J}$ Periodontal Res, v. 29, n. 2, p. 81-94, Mar. 1994.

22. PITARU, S.; SAVION, N.; HEKMATI, H. et al. Binding of a cementum attachment protein to extracellular matrix components and to dental surfaces. J Periodontal Res, v. 27, n. 6, p. 640-646, Nov. 1992.

23. PREISIG, E.; SCHROEDER, H. E. Long-term culture of human periodontal ligament cells with autologous root discs. J Periodontal Res, v. 23, n. 3, p. 211-221, May 1988.

24. RAGNARSSON, B.; CARR, G.; DANIEL, J. C. Isolation and growth of human periodontal ligament cells in vitro. $\mathbf{J}$ Dent Res, v. 64, n. 8, p. 1026-1030, Aug. 1985.

25. SAAD NETO, M.; CARVALHO, A. C. P.; OKAMOTO, T. et al. Reimplante mediato de dentes com a superficie radicular tratada com ácido fosfórico e hidróxido de cálcio. Estudo histológico em ratos. Rev Assoc Paul Cir Dent, v. 40, n. 4, p. 314-320, Jul./Ago.1986.

26. SOMERMAN, M. J.; YOUNG, M. F.; FOSTER, R. A. et al. Characteristics of human periodontal ligament cells in vitro. Arch Oral Biol, v. 35, n. 3, p.241-247, 1990.

27. TENÓRIO, D.; CRUCHLEY, A.; HUGHES, F. J. Immunocytochemical investigation of the rat cementoblast phenotype. J Periodontal Res, v. 28, n. 6Pt1, p. 411-419, Nov. 1993.

28. TERRANOVA, V. P.; PRICE, R. M.; MORISHITA, M. Periodontal regeneration: myth or reality? Int Dent J, v. 41, n. 5, p. 287-294, Oct. 1991.

Recebido para publicação em 15/12/99

Enviado para reformulação em 22/02/00

Aceito para publicação em 18/04/00 